\section{Change blindness}

\author{
Phil Wiffen
}

The Ashmolean Museum in Oxford is the oldest public museum in the world and is well known for its wide range of art and artefacts. It is visited by around one million people each year. This venue became the setting for an interesting piece of research led by a team from Oxford University. Change blindness occurs when changes in images are not noticed by an observer. In other words, we do not accurately record what is in front of us. The team reported their findings in a paper ${ }^{1}$ published in 2018 and observed three main conclusions. First that change blindness occurs when similar objects are viewed briefly in both the real world and then onscreen. Second that the mean levels of change blindness are similar between the real world and onscreen. It happens in both scenarios. The third conclusion was that some scenarios seem to lead to a greater degree of change blindness than other scenarios. The scenarios that produced the greater change blindness had similar designs and similar colours.

Coincidentally a report ${ }^{2}$ on reducing medication harm from the UK government came across my desk in the same week as the change blindness report. This report builds on the WHO 2016 paper titled 'Medication Errors' and quotes a US definition of a medication error as 'any preventable event that may cause or lead to inappropriate medication use or patient harm while the medication is in the control of the health care professional, patient or consumer'. The stated aim of the WHO report is to reduce such errors by $50 \%$ in a 5 -year

Correspondence to Professor Phil Wiffen, Pain Research Unit, Churchill Hospital, Oxford OX3 7LE, UK; phil.wiffen@ndcn.ox.ac.uk period ending in 2021. A commissioned review $^{3}$ to support the working party suggested some figures to underpin the background:

Approximately 237 million medication errors occur in England, of which $72 \%$ have little or no potential for harm. Some 66 million potentially significant errors occur each year-71\% in primary care.

The working group was asked to advise on what actions should be taken to reduce errors, including the following:

- Improving technology such as electronic prescribing.

- Understanding how best to engage patients with their medicines.

- Supporting 7-day clinical pharmacy services in acute hospitals.

- Working with care homes and general practitioners.

- Improving the transfer of information about medicines when patients move between care settings.

The report outlines some interesting observations and challenges for pharmacists and suggests some priority developments. On medicines the report calls for more patient-friendly packaging and labelling, ensuring that computer labelling packages contribute to safer use and use language that is readily understood by patients. To identify and increase awareness of 'look alike, sound alike' medicines and to stop these from occurring in the future.

The report also suggests a research agenda which includes reducing avoidable hospital admissions due to medication, enhancing patient engagement in relation to medication and developing a robust definition of medication-related harm.
Any attempt to reduce medication-related harm is to be welcomed; however, the issue of change blindness is also important here. People often see what they want to see and subtle differences can be missed. Issues of labelling, colour coding and presentation have long been discussed within pharmacy, but there has been more heat than light. Change blindness research suggests that we can miss important things both in the real world-items on the bench-and online in managing the processes. I suspect the frequent changes of packaging that professionals and patients experience due to generics add a dimension to the issue. We owe it to the people we serve to eliminate change blindness and ensure that we maintain that old pharmacy adage of 'Right Patient, Right Drug, Right Dose, Right Time'.

\section{Competing interests None declared.}

Provenance and peer review Commissioned; internally peer reviewed.

(C) European Association of Hospital Pharmacists (unless otherwise stated in the text of the article) 2018. All rights reserved. No commercial use is permitted unless otherwise expressly granted.

\section{(A) Check for updates}

To cite Wiffen P. Eur J Hosp Pharm 2018;25:117.

Eur J Hosp Pharm 2018;25:117.

doi:10.1136/ejhpharm-2018-001587

\section{REFERENCES}

1 Attwood JE, Kennard C, Harris J, et al. A Comparison of Change Blindness in Real-World and On-Screen Viewing of Museum Artefacts. Front Psychol 2018;9:151.

2 The Report of the Working Group on reducing medication-related harm. 2018. https://assets. publishing.service.gov.uk/government/uploads/ system/uploads/attachment_data/file/683430/shortlife-working-group-report-on-medication-errors.pdf (accessed Apr 2018).

3 Elliott R, Camacho E, Campbell F, et al. Prevalence and Economic Burden of Medication Errors in the NHS in England. Rapid evidence synthesis and economic analysis of the prevalence and burden of medication error in the UK: Policy Research Unit in Economic Evaluation of Health and Care Interventions. Universities of Sheffield and York, 2018. 